\title{
DEVELOPMENT OF HIGH-TECH ENTREPRENEURSHIP ECOSYSTEM: CASE OF UNIVERSITY OF NOVI SAD
}

\author{
Đorđe Ćelić ${ }^{1}$ \\ Zorica Uzelac ${ }^{2}$ ii \\ Zoran Drašković ${ }^{3}$
}

DOI: https://doi.org/10.31410/LIMEN.S.P.2019.99

\begin{abstract}
High-tech entrepreneurship is one of the means by which new knowledge and technologies are converted into economic and social benefits. This paper presents bottom-up development of high-tech entrepreneurial ecosystem in transitional economy through the example of the city of Novi Sad, and the University of Novi Sad, Serbia. Entrepreneurial ecosystems are defined as sets of interdependent actors and factors coordinated in such a way that they enable productive entrepreneurship within a particular territory. Current scientific literature which examines high-tech startup ecosystems is underdeveloped. Most of the papers are focused on superficial generalizations based on successful case studies such as Silicon Valley and Boulder in USA, Tel Aviv in Israel, Berlin in Germany or Beijing in China, while neglecting the state of high-tech ecosystems in developing countries. In this paper the authors present the state of development of one such high-tech ecosystem, which is of great importance to Serbia.
\end{abstract}

Keywords: Startups, Transitional economy, High-tech entrepreneurial ecosystem.

\section{INTRODUCTION}

$I^{1}$ $\mathrm{n}$ the last few decades we are witnessing importance of the research in the area of high-tech sectors and there are many studies which show that high-tech entrepreneurship is one of the vehicles by which scientific results are translated into economic benefits.

Another problem stems from the fact that most of the scientific work deals with small and medium-sized enterprises in general: „Policy references to entrepreneurship are typically equated with SMEs in general or even numbers of self-employed. Neither of which fully captures the totality and complexity of entrepreneurship." (Nepelski \& Roy, 2017).

Contemporary literature emphasizes that current policy support does not sufficiently recognize the role of specifically high-tech entrepreneurship vs. low tech entrepreneurship.

Many of the studies have analyzed general conditions necessary for the development of entrepreneurship in general (Mason, Colin; Brown, 2014). Given the obvious difference between high-tech and low-tech entrepreneurship, there is a lack of analysis of the impact of the global environment and the necessary conditions for the successful operation of high-tech companies.

The main problem is the fact that most of the studies are devoted to research related to small and medium-sized enterprises in developed countries. There is a lack of analysis of the difficulties

\footnotetext{
$1 \quad$ Faculty of Technical Sciences, University of Novi Sad, Trg Dositeja Obradovića 6, 21000 Novi Sad, Serbia

2 Faculty of Technical Sciences, University of Novi Sad, Trg Dositeja Obradovića 6, 21000 Novi Sad, Serbia

3 Faculty of Technical Sciences, University of Novi Sad, Trg Dositeja Obradovića 6, 21000 Novi Sad, Serbia
} 
associated with SMEs in developing countries, and especially a lack of research on high-tech entrepreneurial ventures.

In the paper "Determinants of high-tech entrepreneurship in Europe" the authors mentioned that Europe was lagging behind in the ICT sector which was the driver of growth in the late 1990s in the US (Cincera \& Veugelers, 2013).

The authors (Moncada-Paternò-Castello, 2016) emphasize that this pattern can be generalized to most emerging sectors in which European firms are unable to benefit from first mover advantages. To bridge this gap, it is necessary to develop a high-tech entrepreneurial ecosystem to support and facilitate the development of new high-tech firms in these emerging sectors. One of the basic resources for the development of high-tech entrepreneurship is domain knowledge in the field of ICT, and it is therefore natural that the high-tech entrepreneurship ecosystem develops around the universities that create that form of domain knowledge. In addition to this resource, it is necessary to provide other resources necessary for the development of high-tech ventures (Nepelski \& Roy, 2017): Entrepreneurial culture, Entrepreneurial education, Intellectual property rights (IPR) protection, Market dynamics, Access to finance, Regulatory environment, Physical infrastructure.

Given that high-tech entrepreneurship is a generator of economic development in the knowledge economy, knowledge intensive organizations deserve the utmost attention when formulating public policies, in both developed and developing economies. Therefore, understanding the differences between the framework conditions for successful entrepreneurship and high-tech entrepreneurship is of great importance and is a challenge for scholars and policy makers.

It is necessary to define the specific barriers that hinder the development of new high tech firms, as they play a key role in improving competitiveness; "one of the greatest engines fostering economic growth in the global economy is high-tech industry" (Frenkel, 2012).

Dynamic regional economies like Silicon Valley and Boulder in USA, Tel Aviv in Israel, Berlin in Germany or Beijing in China were seen as evidence of the transformative effect that technology clusters can have on regional economies by accelerating the growth of technology startups.

Although it is widely accepted that the high-tech industry is the biggest driver of economic growth in the global economy and generator of dynamic regional economies and technological startups, there is still "a lack of research to identify the nature of high-tech firms which are often viewed as something of a "black box"”'(Brown \& Mason, 2014).

The focus of this study is high-tech entrepreneurship ecosystem developed around University of Novi Sad.

The characteristic of such an ecosystem is that it is made up of more sophisticated, science-based firms whose R\&D-based innovation support program is affiliated with universities, rather than most SMEs in traditional sectors with more ad hoc innovation processes (Brown \& Mason, 2014; Tödtling, Lehner, \& Kaufmann, 2009). 


\section{CASE STUDY REVIEW}

University of Novi Sad was established in 1960. It currently has more than 50,000 students, 5,000 employees and more than 400 study programs. The largest faculty within the University of Novi Sad is the Faculty of Technical Sciences which has over 15,000 students and over 1,200 employees.

The Faculty of Technical Sciences is guided by the idea of the "Holy Trinity rule". This unwritten rule implies that faculty employees distribute their activities evenly according to the following formula: $1 / 3$ teaching; $1 / 3$ research; $1 / 3$ industry cooperation. The rule has contributed to developing intensive cooperation with the economy, leading to the development of innovative solutions in response to industry needs. The newly created innovations also serve as a basis for improving the teaching process at the Faculty.

\section{PHASES OF DEVELOPMENT OF THE ENTREPRENEURIAL ECOSYSTEM}

Due to the economic sanctions imposed on Serbia in the 1990s, industrial companies approached the University to find new solutions for maintaining and upgrading industrial plants and overcoming the lack of spare parts.

During this period, 18 companies were founded (mostly by professors) at the University of Novi Sad, most of them spinoff companies of the Faculty of Technical Sciences.

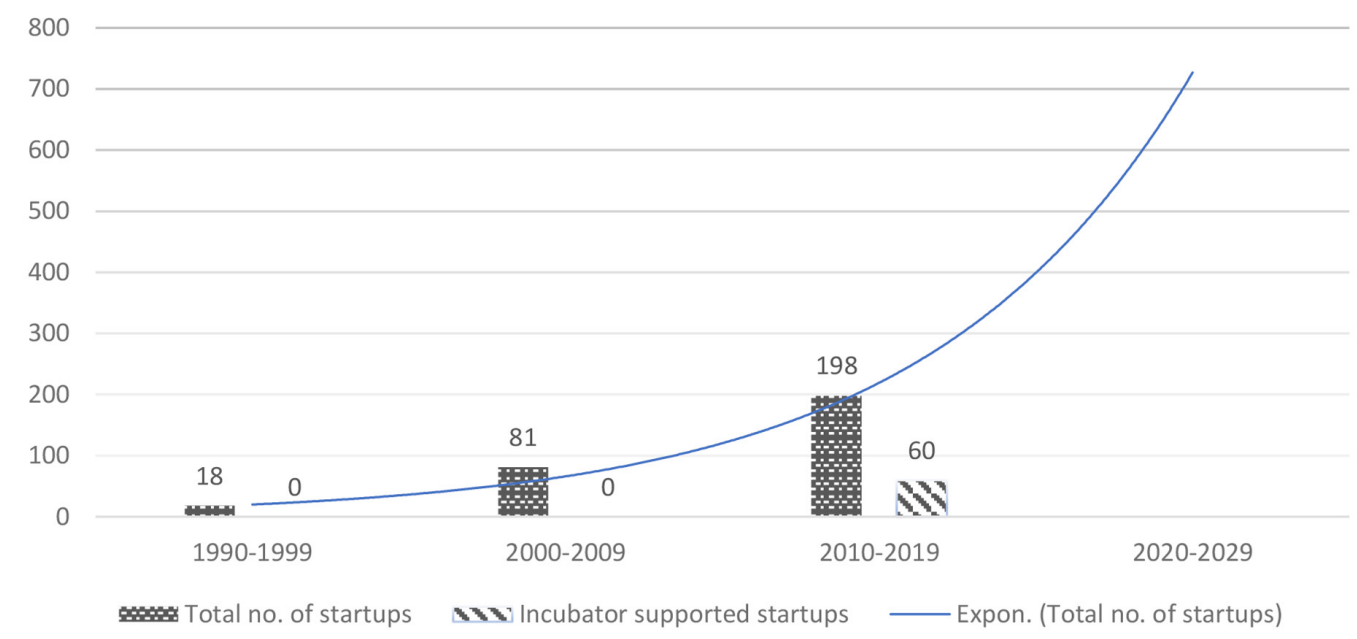

Figure 1 - Results of high-tech entrepreneurship ecosystem of University of Novi Sad - Number of startups per decade

Source: Authors based on publicly available information from Serbian Business Registers Agency

After the sanctions were lifted, new cooperation was established between former industry suppliers (before sanctions) from abroad, and professors who maintained industrial systems in the 1990s. Finding solutions and keeping companies afloat under sanctions required lots of improvisation and innovation. Companies from abroad recognized that quality.

In the 2000-2009 period, many of the Serbian industrial companies disappeared through the process of privatization, but the spin-offs continued to develop through the cooperation with international partners. 
New spin-off companies in Phase II were mostly established by professors, researchers, and former employees of companies from Phase I (1990's). In the 2000-2009 period 63 new high-tech companies were established.

During the Phase III from 2010 to 2019 most of the industry from which the first generation of spin-off firms have evolved has disappeared, and new spin-off and startup firms continue to develop on the wave of cooperation with foreign partners, mostly based on outsourcing business model.

New firms are being founded by professors, assistants, and former employees of Phase II firms. Most of the companies are in the field of ICT and many are founded by professors from the Faculty of Technical Sciences. The Faculty of Technical Sciences has greatly contributed to the development of high-tech ecosystems by investing heavily in the development of new ICT study programs that have followed world trends and enabled this sector to develop by providing skilled professionals. During this phase of development, the Faculty of Technical Sciences participated in the establishment of the Business Incubator Novi Sad with the aim of institutionalizing support for the development of new high-tech startup companies. As a result of the activities in the Phase III of ecosystem development, a total of 117 new companies were established, of which 60 new startups were founded with the support of the Incubator (Figure 1).

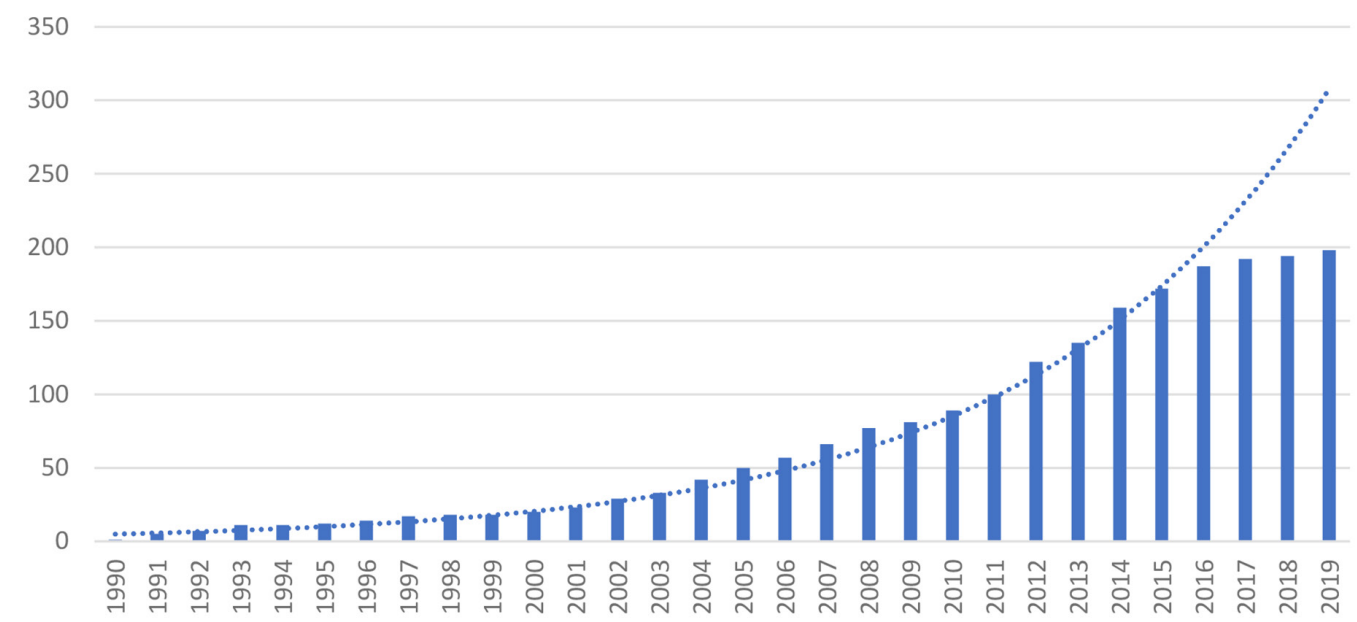

Figure 2 - Results of high-tech entrepreneurship ecosystem of University of Novi Sad - Total number of companies per year

Source: Authors based on publicly available information from Serbian Business Registers Agency

Figure 2 shows the total number of high-tech companies from 1990 to 2019. The picture shows the exponential growth of the number of high-tech companies until 2016. The stalled growth occurring in the period from 2016 can be linked to the capacity limits related to the number of enrolled students and graduates of ICT majors from the Faculty of Technical Sciences.

Figure 3 gives an overview of the total number of startups that were created with the direct support of the Business Incubator Novi Sad. Interestingly, an exponential upward trend can be observed here as well. The trend deviation in 2018 is due to the limited space capacities of the Business Incubator Novi Sad. This limitation will be alleviated with additional space for the Business Incubator Novi Sad within the new Science and Technology Park Novi Sad, which is scheduled to open in mid-2020. 


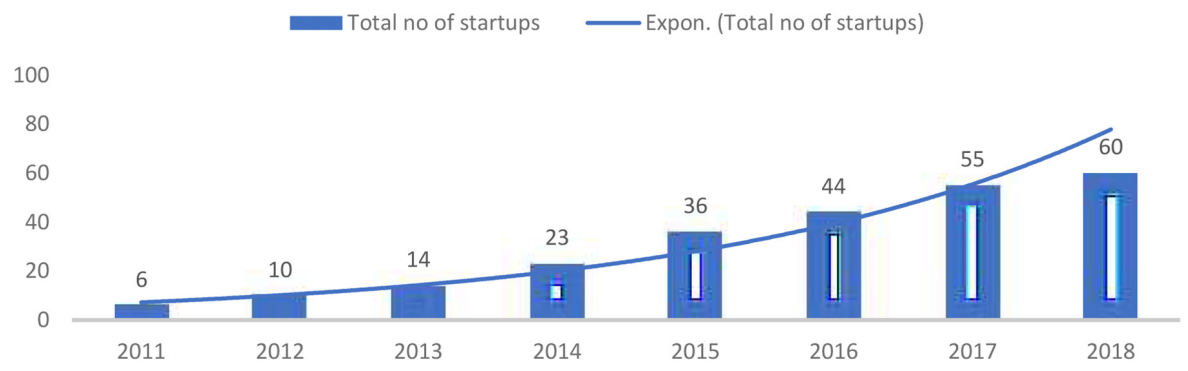

Figure 3 - Results of Business incubator Novi Sad - number of startups per year

Source: (Ćelić, Uzelac, Draskovic, Petrov, \& Janjušić, 2019)

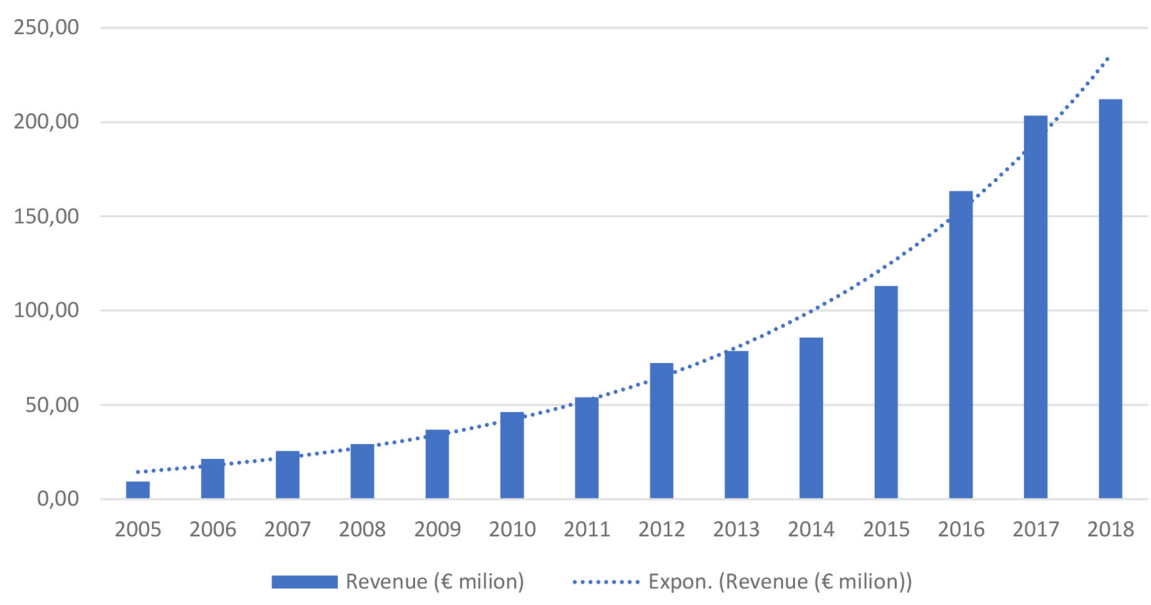

Figure 4 - Results of high-tech entrepreneurship ecosystem of University of Novi Sad - Total revenue Source: Authors based on publicly available information from Serbian Business Registers Agency

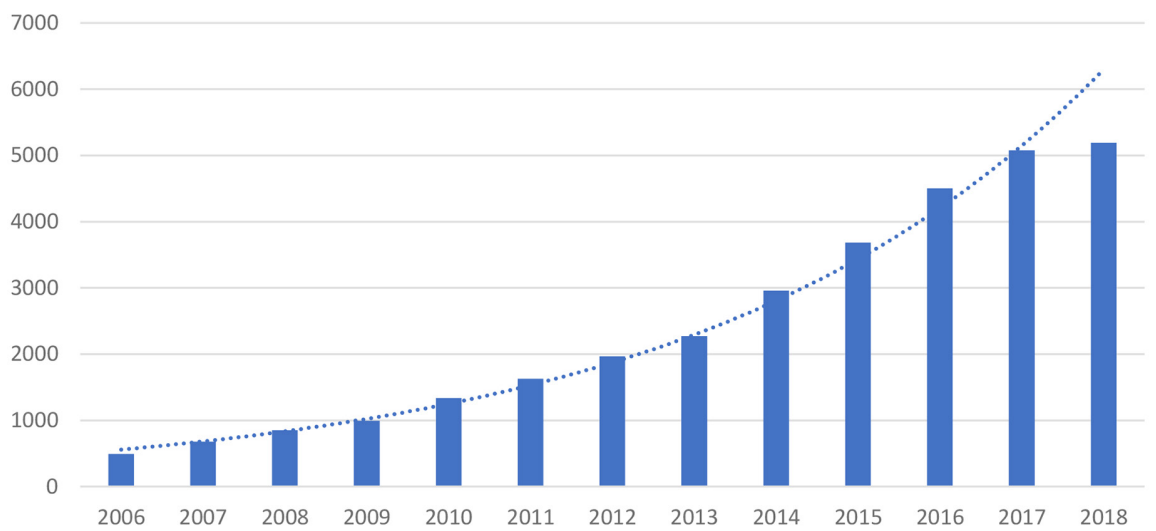

Figure 5 - Results of high-tech entrepreneurship ecosystem of University of Novi Sad - Total number of employees

Source: Authors based on publicly available information from Serbian Business Registers Agency

Figure 4 shows the total revenues of companies from high-tech ecosystem, and it can be observed that the revenue growth follows exponential trend.

Figure 5 shows the total number of employees of high-tech companies for the period 2006 to 2018, and it can be observed that the growth has an exponential trend until 2017. Deviation from the trend observed in 2018 can be linked to the limits in the number of students who are graduating from ICT majors at the University of Novi Sad. 


\section{CONCLUSION}

Importance of the high-tech ecosystem that has grown around and with the help of the University of Novi Sad for the local and regional economy cannot be underestimated. It has greatly reduced the brain drain in the whole province of Vojvodina. Some of the high-tech companies that have sprouted from this ecosystem have become major economic forces not just on the local or regional stage, but on the global as well. The best example is the company DMS Novi Sad with over a thousand employees, most of them current and former students of Faculty of Technical Sciences. DMS Novi Sad has been founded by professors from the Faculty of Technical Sciences. It has recently been acquired by Schneider Electric (French multinational corporation), and is now known as Schneider Electric DMS NS LLC.

Figure 2 shows the slowdown in the exponential growth of the number of startups in the hightech ecosystem of the University of Novi Sad, and Figure 5 shows the same trend when it comes to the total number of employees in the high-tech companies of this ecosystem. Both growth stunts are due, among other things, to the limits in the number of newly graduated ICT professionals due to the limited capacity of Faculty of Technical Sciences, the most significant institution that trains ICT professionals at the University of Novi Sad. Fortunately, Faculty of Technical Sciences, and Business Incubator Novi Sad will get significant additional space within the Science and Technology Park of Novi Sad in mid-2020. That is expected to significantly increase their educational and support capacities, and thus enable the trend of exponential growth of both high-tech companies and number of employees within the high-tech ecosystem of the University of Novi Sad to continue.

\section{REFERENCES}

Brown, R., \& Mason, C. (2014). Inside the high-tech black box: A critique of technology entrepreneurship policy. Technovation, 34(12), 773-784. https://doi.org/10.1016/j.technovation.2014.07.013

Ćelić, Đ., Uzelac, Z., Draskovic, Z., Petrov, V., \& Janjušić, D. (2019). Development Support for High-Tech Start-ups: Case Study Business Incubator Novi Sad. In Conference Proceedings of The $8^{\text {th }}$ PAR International Scientific-Professional Leadership Conference - Business Angels Impact on Global Entrepreneurship (pp. 343-353). Opatija.

Cincera, M., \& Veugelers, R. (2013). Young leading innovators and the EU's R\&D intensity gap. Economics of Innovation and New Technology, 22(2), 177-198. https://doi.org/10.1080/104 38599.2012 .731166

Frenkel, A. (2012). Intra-metropolitan Competition for Attracting High-technology Firms. Regional Studies, 46(6), 723-740. https://doi.org/10.1080/00343404.2010.529120

Mason, Colin; Brown, R. (2014). Entrepreneurial Ecosystems and Growth Oriented Entrepreneurship. Oecd, 1-38. https://doi.org/10.1007/s13398-014-0173-7.2

Moncada-Paternò-Castello, P. (2016). Sector dynamics and demographics of top R\&D firms in the global economy. https://doi.org/10.13140/RG.2.2.19739.46881

Nepelski, D., \& Roy, V. Van. (2017). Determinants of high-tech entrepreneurship in Europe Innovation and Employment View project ICT Industry Analysis View project. https://doi. org/10.2791/96153

Tödtling, F., Lehner, P., \& Kaufmann, A. (2009). Do different types of innovation rely on specific kinds of knowledge interactions? Technovation, 29(1), 59-71. https://doi.org/10.1016/j. technovation.2008.05.002 